Journal Homepage: $-\underline{w w}$.journalijar.com
ANTERNATIONAL JOURNAL OF
ADVANCED RESEARCH (IJAR)
Article DOI: $10.21474 / \mathrm{IJAR} 01 / 2268$
DOI URL: http://dx.doi.org/10.21474/IJAR01/2268

RESEARCH ARTICLE

\title{
APPLICATION OF MUGHAL JAALI DESIGNS OF AGRA ON TEXTILESA SURVEY IN A TEXTILE INDUSTRY.
}

Meenakshi Kumar Seth ${ }^{1}$ and Dr. Parul Bhatnagar ${ }^{2}$.

1. Research Scholar, Textile Design, Dept. of Drawing \& Painting, Dayalbagh Educational Institute.

2. Asst. Professor, Textile Design, Dept. of Drawing \& Painting, Dayalbagh Educational Institute.

\section{Manuscript Info}

Manuscript History

Received: 29 September 2016

Final Accepted: 30 October 2016

Published: November 2016

Key words:-

Mughal Jaalis, Textile Design, Classical,

Contemporary, Interpretation

\begin{abstract}
In the existing state of competitive market and textile design techniques, the designers need to acclimatize some contemporary practices to keep our heritage art, craft, designs and motifs alive. Designers and crafts persons today endure to discover, rejoice and reproduce our rich original substantial art and crafts of heritage with the numerous ways and forms of textile design. This research paper would expedite the renewed stream of ideas in the area of contemporary styles in textile design by constructing novel and more resourceful connections between past and present.

With the new advanced ideas, the potentials to redesign the magical old classical designs, there is an incredible scope in the form if Mughal Jaalis. The patterns can generate abundant variations, which may bring in series of re-construction of heritage designs in form of contemporary creations. This research will reconnoiter that in which field of textile design and with what kind of interpretation, the Jaali patterns of Agra's Mughal architecture are being and can be used.
\end{abstract}

Copy Right, IJAR, 2016,. All rights reserved.

\section{Introduction:-}

Historic buildings and their designs have always been a foundation of creativity to young textile designers and crafts persons. One such foundation of creativeness is the 'Mughal Jaalis'-the best matchless feature of Agra's Mughal constructions (Figure 1).

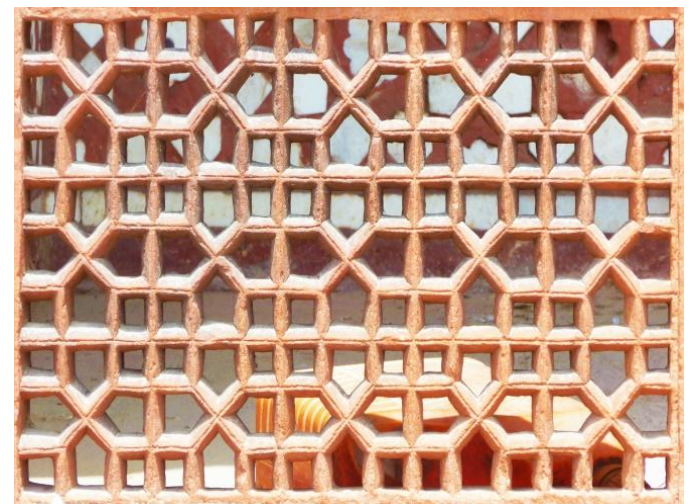

Figure 1:-A Typical Mughal Jaali of Itmad-ud-Daulah

Corresponding Author:-Meenakshi Kumar Seth.

Address:-Research Scholar, Textile Design, Dept. of Drawing \& Painting, Dayalbagh Educational Institute. 
Mughal Jaalis of Agra are the substantial highlight of architectural aesthetics in Agra. Amongst the lavish and resourceful masterpieces of Mughal Architecture in India, the utmost exceptional and incredible are the monuments of Agra; constructed and designed in the $16^{\text {th }}$ and $17^{\text {th }}$ century with the fusion of Indian, Islamic, Persian and Turkish styles, with tremendous brilliance and class. Krista Danes denotes in her article that during the Mughals rule in the subcontinent in $15^{\text {th }}$ to $18^{\text {th }}$ centuries they left the whole lot of pieces of their construction and design so that they could be reminisced. " Krista claims that the Mughal art is still unique and no one has ever been able to make such creative pieces till today.

Agra is a town of tombs and monuments. With the presence of these buildings in most of the part of the city, one can identify a range of architectural details in their characteristic classic designs and patterns. The model examples are the various Jaalis of- magnificent TajMahal, splendid Akbar's mausoleum at Sikandara, the incredible Itmad-udDaulah and the utmost creative of all with assortment of adornments and designs, Jaalis of FatehpurSikri.

VaruniKhosla states, "Product Designers are looking back in time to add a royal opulence to your home." So the distinguishing archetypal structures from our heritage appear to play an active role in cultivating the creativity in wider means. Deborah Thiagarajan endorses this by saying, "Contemporary Indian Designers have unique advantage. They are surrounded by a living tradition and skilled crafts people, making experimentation and change easy, relatively inexpensive and literally at their fingertips." "The Mughal emperors being lovers of fine arts had evolved new styles and techniques which indicate a happy mingling of Persian and Indian elements. This synthesis has left a deep impression on painting, architecture, embroidery, jewelry and metal work of the age. All the fine arts of the period breathe a spirit of luxury." 3

The importance of Jaali designs does not only symbolize its functionality but also the creative cultural values. The Jaali patterns of several Mughal monuments in Agra in context with visual aspects are categorized in a form of cultural manifestation. "Designers have a responsibility to keep alive India's rich heritage of glorious textiles", declares DeepikaGovind, a Fashion Designer. ${ }^{4}$

BrindaSuri explains, "If one were to select a textile influence that has emerged stronger over the centuries the Mughal genre would be a clear winner. Its attractive motifs echo across the textile spectrum making up the bulk of admired patterns on view in the country. This especially holds true in the block prints, weaves and embroideries largely seen in the metros and regions in the north, east and west India that were once under the Mughal reign." 5

Patterns initiated from Mughal Jaalis have taken place in various industries, like creative crafts and arts, fashion, and significantly on textiles. Such a creation of products plays a commendable role in sustaining the ancient heritage. Implementing modern styles with our old designs validate the survival of these remarkable master pieces.

Interior Designer SarthakSengupta of Sahil and Sarthak Design elucidates, "Mughal motifs infused with contemporary designs make for statement pieces. Mughal style does not always translate into overtly ornate furniture or extremely busy prints, especially if the designer has used these patterns discreetly." 6

\section{The Application of Mughal Jaalis on Textiles:-}

The design elements inspired from the patterned Jaalis of Mughal monuments are reasonably significant as these stimulate our creative attitudes encouraging us to think in more imaginative and different methods. An eminent blog spot states, "Geometrical designs inspired from various Turkish and Mughal monuments can be found sitting on a number of dresses and famous Mughal Jaalis have found expression in many a designer's works."7

The application of Mughal Jaali patterns on textiles would benefit the budding designers to have an insight into historic culture and would in turn reproduce its creative practices on present day textiles. It would determine new

${ }^{1}$ (Danes Krista, www.selfgrowth.com)

2 (Thiagarajan Deborah, The Challenges Ahead,1999)

3 (Jayapalan N, Social and Cultural History of India since 1556)

4 (Govind Deepika, DNA, 2011)

5 (Suri Brinda, Mughal Motifs, 2010)

${ }^{6}$ (Graffiti, 2013)

7 (Kunal) 
methods through which these Jaali forms may be implemented on variety of textile products getting useful results in the textile industry. Dr. ParulBhatnagar specifies this in her book-'Traditional Indian Costumes and Textiles', that "A fresh modification of the old motif and style, ornamentation or design is generally how innovation is accepted in designing."

Creative re-adaptation of Mughal Jaalis is developing into one of the considerable characteristic of contemporary designing. New designers are using the Jaali designs and patterns on textile products and merchandises in variety of forms and techniques.

Presently the Indian textiles represent the unique balance of classics and modernity. Textiles produced with the types of variations in embellishment in the existing times not only replicate our opulent past but also equip to the presentday requirements. Blending classical patterns with the contemporary ideas produce masterpieces generating a hallmark in the modern world of textiles. With the use of digital designing, the historical Jaali patterns of Mughal monuments have taken up the new projections in textile industry.

Many well-known Export Houses, Indian designers, Crafts Persons and Brands are creating the designs inspired by Mughal Jaalis of Agra (Figure 2). These styles of experimentations have rejuvenated the Mughal art to greater standards in terms of Embroidery, Weaving, Printing and Painting.
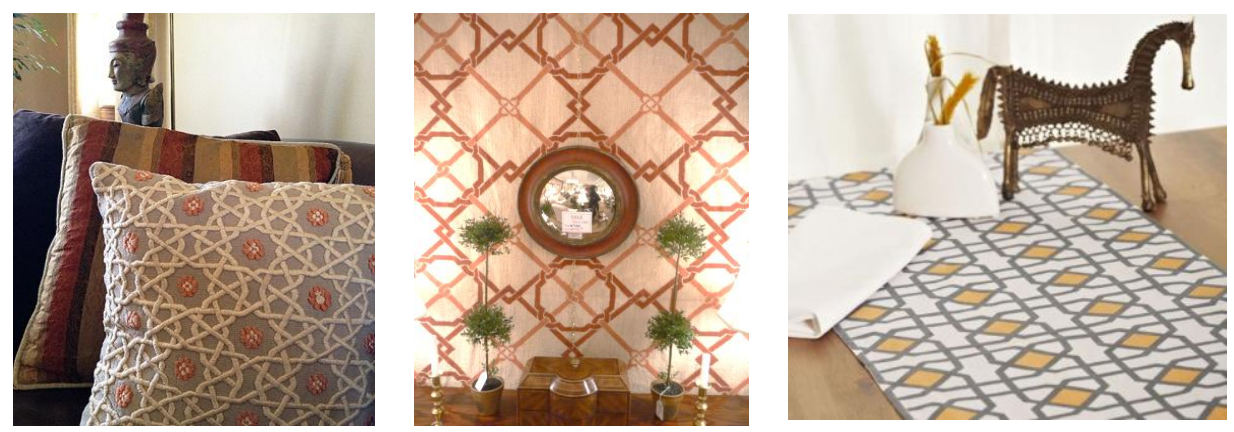

Figure 2:-Contemporary Textiles Inspired by Jaali

\section{Sample Size and Description:-}

The study comprises evaluation of 10 Jaali designs taken from various Mughal Monuments of Agra - TajMahal, Sikandara, Itmad-ud-Daulah\&FatehpurSikri. These Jaali patterns are recognized on plentiful present and traditional textile merchandises. The samples are taken as various textile products and were separated into 4 skills of Textile Construction and Ornamentation i.e- Embroidery, Weaving, Painting and Printing. 25 samples from each technique were observed whether contemporary or traditional.
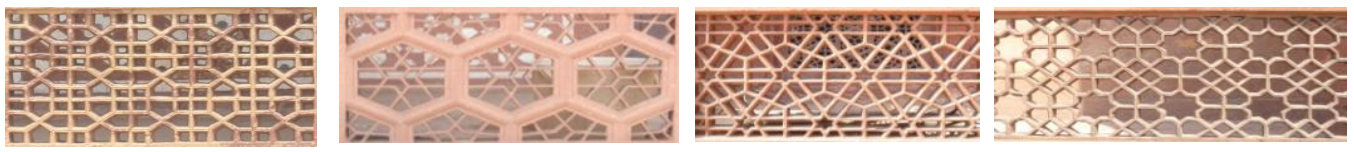

Following Jaali patterns were observed to achieve the results:
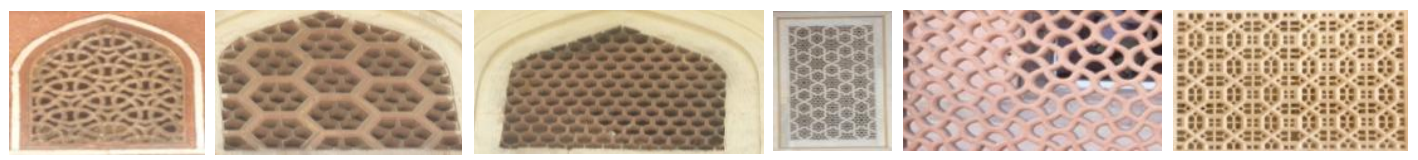

Figure 3:-Jaali Patterns taken for Sampling

\section{Implementation of Jaali Patterns on Textiles with Different Techniques:-}

Indian textile production has observed major changes since past three decades. Globalization and growth of markets, has enabled the aesthetic feature attain abundant distinction, rising the competitive markets to the innovative heights. With the consistent up gradation of applications and practices there is an unending increase in demands from the customers, which not only increments the value to the products but also creates a trademark. Accomplishing this requisite the craftsmen need to generate an extra value to their products. From each part of the country, from 


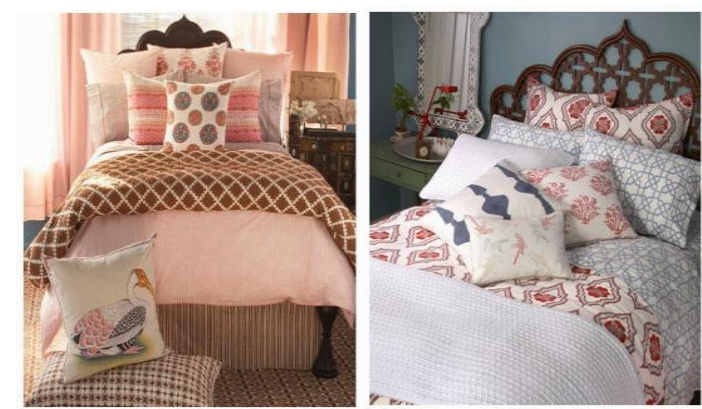

Figure 4:-Familiarities with Jaali Patterns

rural to urban limits embroiderers, weavers, printers and painters continue to treasure their textile traditions with the spark of embellishment and ornamentation comprising the amalgamation of different techniques reproducing the classical lifestyle of India.

Every particular design and motif used in the construction of these magnificent heritage edifices carry a distinct dominance in the fabrics, apparels and textiles (Figure 4), specifically the design components availed from the ornamental Jaalis of Mughal Monuments of Agra.

This part of the paper is focused on Indian Contemporary and Traditional Textiles which are identified with Jaali patterns inspired by Mughal Jaalis. The observation started with the recognition of Jaali patterns on Embroidered Textiles as these set up the major part in the entire fields of textile industry like apparels, home furnishings, accessories.

\section{Embroidery with Jaali Patterns:-}

Virtually everything or any design can be created with this technique. From linear patterns to stylish illustrative compositions, all types of patterns can be created with embroidery. In recent times, embroidery motifs and patterns have received much importance and appreciation in the global fashion industry. This has initiated the use of sophisticated machines, especially for creating repeat patterns. Not only in apparels, embroidered fabrics are outstandingly used in the modern styles and have proven their existence in nearly all the areas of textile industry, exclusively in the arena of home furnishings.

Reconnoitering embroidery techniques from past to present, it has developed into volumes with respect to motifs, patterns, designing and technology.

Jaali Patterns in Traditional Indian Embroidered Textiles:-

Jaali pattern can be easily familiarized with Indian traditional textiles, mainly in geometrical forms with variety and different exemplification. Although the methods may vary depending on the cultures and states, the elementary feature of geometrics can definitely be witnessed in different traditional embroideries, similar to the Mughal Jaali patterns.

Following are the several traditional embroideries of India which are identified with the features of Jaali designs. Most of the designs are geometrical, typically in abstract form and some are done with stylized floral patterns.

Chikankari: The best popular Jaali work done with the thread on textiles is the Chikankari. This style of craft is also known as 'Shadow Work' and is instigated from Lucknow (Uttar Pradesh).

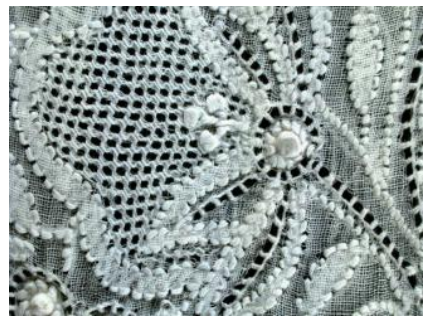

Figure 5:- 2Jaali work in Chikankari

The craft is more than 200 years old and the embroidery is recognized for its eternal grace and transparent delicacy. The embroidery is traditionally done with the use of white untwisted thread on off-white or light colour muslin fabric. It is supposed that Mughal Emperor Jahangir's queen Noor Jahan, took an exceptional attention in Turkish 
architecture, their wide-ranging designs and the visual effects of concrete Jaali (lattice screens) charmed her. The stimulus of creating chikankari was a result from desire to replicate the concrete lattice or Jaali screens on to the fabric. Such lattices or Jaalis created in Chikankari generate a look of open net or mesh fabricated by carefully placing the warps and wefts separately with needle without cutting or pulling of thread, forming neat regular holes or Jaalis on the fabric (Figure 5). Maximum of the motifs and design in Chikankari are enthused from Mughal Jaalis.

Phulkari:Phulkari is a traditional form of embroidery from the culture of Punjab. 'Jat' migrants of Central Asia brought Phulkari to India. Phulkari embroidery is a folk practice of Punjab people. The technique involves lot of features and forms made in grids motivated by geometrical elements in designing, by using darn stitch creating a similar look of Jaali.

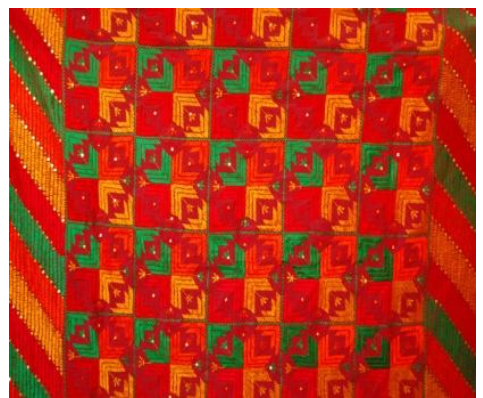

Figure 6:-Resemblance of Jaali in Phulkari

"These pieces are virtuoso examples of embroidery with skillful variations of geometric patterns with in the overall grid. These design share a common vocabulary with the Jaali screen or lattices of Mughal architecture. ${ }^{8}$ (Figure 6)

Toda Embroidery: This exceptional embroidery is practiced by Nilgiri tribes of Tamilnadu known as 'Toda'. The embroidery is done on white or off white fabric in red and black combination of threads. The embroidery is so fine that it appears as weaving (Figure 7).

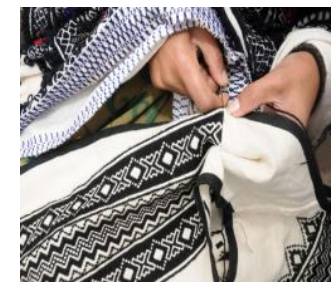

Figure 7:-Toda Embroidery

Locally called 'pugur' (meaning flower), this style of embroidery is done by tribal women and men on shawls. Patterns used are very much alike Mughal Jaali patterns. But there is no association amongst the two art forms. The inspiration for this form of embroidery is supposed to be of Greek origin.

Zardozi:Zardozi is an antique craft and is an old form of hand embroidery. This type of embroidery is done in India, Pakistan and Bangladesh as these provinces were the part of Mughal Kingdom and culture, mainly in the era of Mughal ruler Akbar. Even though many Mughal motifs are patterned in Zardozi embroidery, the finest is the delicate Jaali (net) fashioned on certain parts of the fabric. Zardozi usually represents geometric forms along with flowery patterns (Figure 8).

Today Zardozi has advanced into a significant component of contemporary fashion and has risen up to the international boundaries. The usage of Zardozi embroidery can be seen in European fashion too. Besides apparels Zardozi has also become very prevalent in the other areas of the textile industry like- draperies, accessories and home furnishings.

${ }^{8}$ (Jasleen) 


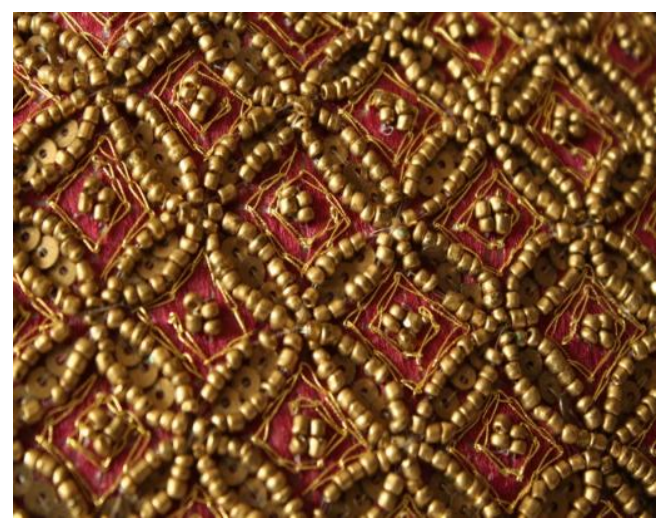

Figure 8:- Jaali Pattern in Zardozi

A project was commenced to apprehend the Jaali pattern with the technique of Zardozi embroidery. Variety of products were designed and created with Jaali patterns to bring out the desired results (Figure 9, 10)

Following are some of the illustrations of the completed project:

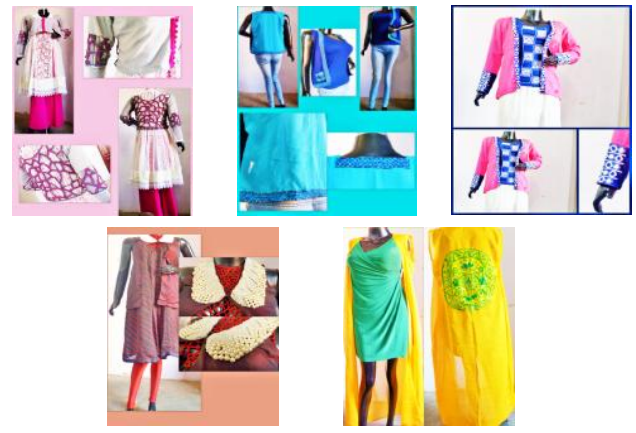

Figure 9:-Costumes designed with Jaali Patterns
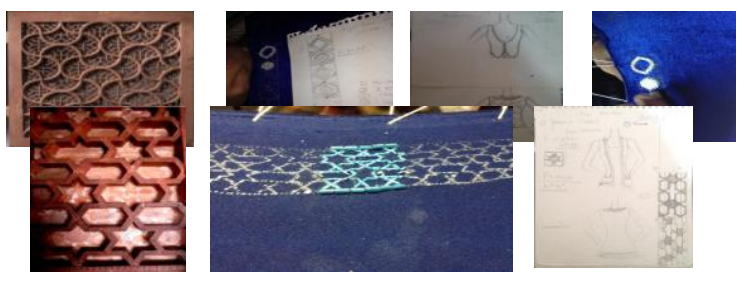

Figure 10:-Project Development

Analysis:-
The attempt was made to make series of female apparel to make a collection on Jaali
All the tailored attires were of contemporary style.
- The technique implied on the samples was "adda work" done in Zardozi embroidery.
- The patterns reconstructed were all customized to bring out the anticipated effects.

Results:

* The refabricated Jaali patterns were presented into absolutely novel style.

* It was observed that not only the complete fabric can be created with such patterns but any part of the garment or apparel can be fashioned with such unique patterns.

\section{Painting:-}

Painting on textiles is done for both fine art and craft presentations. Painting on textiles is a convenient and easy method to generate and form designing ideas by which one can meet vast opportunities to transform the creativity. Extensive variety of textiles is mass-produced all over the world with plentiful techniques. These techniques are subject to climatic conditions, cultural backgrounds and accessibility to raw materials along with the trade contacts. But painting is a technique which can be used without depending upon any such element. Although Mughal Jaali patterns could not be observed anywhere in traditional painted textiles of India, but considering the modern styles and practices, various projects were taken into observation comprising Mughal Jaalis as the authentic source of inspiration to create range of textile products.

A study was conducted on the Diploma students of Textile Design in Dayalbagh Education Institute, Agra. Students were given a project to observe original Jaali patterns of Agra's Mughal Monuments. The objective was to form something new and different to compliment these patterns with the help of painting technique. The students decided to make the composition with mask and the original Jaali patterns (Figure 11). 


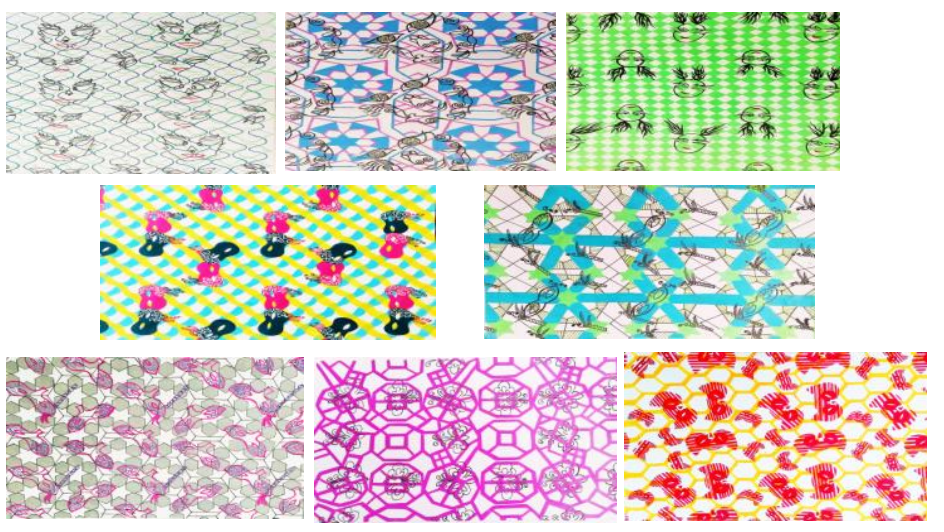

Figure 11:-Jaali Designs Recreated by Students

They chose to design a multiuse fabric with repeat method on A4 size Ivory Sheet. There were 17 students and they all ended up with range of designs of rare kind.

\section{The Observation:-}

* All the original Jaali patterns were replicated.

* Most of the patterns were recreated by using a colour scheme or harmony.

* Masks were simply used to highlight the Jaali patterns.

\section{Result:-}

It was observed that today, even after such development in skills, techniques and modernization in designs, the young generation is still connected to those same geometrical patterns which were structured 100s of years. Without changing them much the students transformed the original patterns into unique contemporary ones. The students were delighted to take the inspiration from our heritage buildings and added a modern touch by simply highlighting the original patterns with the repeats of masks. Thus it proves that while designing repeats the Islamic geometric patterns would be of great assistance as they itself are created with mathematical order and technical repeats of geometry. Variety of geometric repeats can be regenerated by following the Jaali patterns with a sensible approach.

\section{Printing:-}

The technique of applying colour to the fabric in a designed pattern is known as Printing on textiles. There are numerous methods which are applied to do printing. The most commonly used techniques are screen printing, stencil printing, wood block printing, roller printing and engraved plates printing. Looking back at our Indian customs, there have been many states where printing has traditionally been done especially with blocks. Owing to the less cost and easy applicable technique and bright colour effects, lots of designers are attracted to this textile ornamentation technique (Figure 12). 1

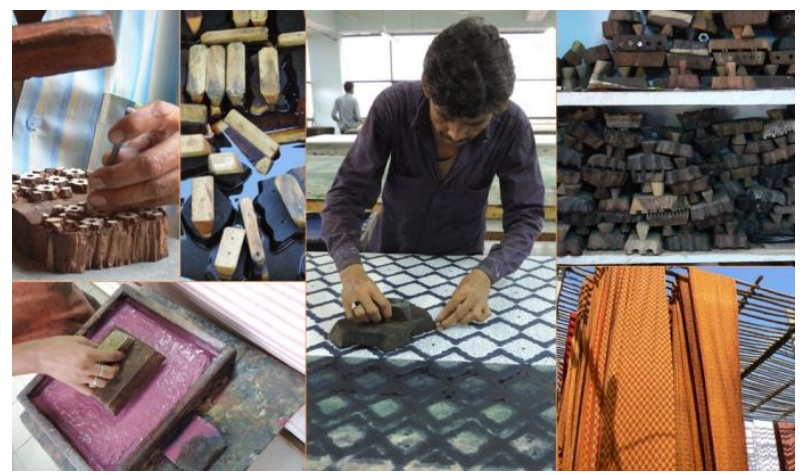

Figure 12:-Block Printing inspired by the Decorative Architectural Elements of Mughal Jaalis The initial and the most regular use of Jaali patterns can be seen in the Saudagiri Printing. 
Saudagiri Printing:Block Printed Saudagiri fabrics were manufactured in Gujrat and exported in Siam market during $19^{\text {th }}$ century (Figure 13). Saudagiri is the Persian word, means 'goods for sale'. This technique employs dyed fabrics used for 3 colour printing.

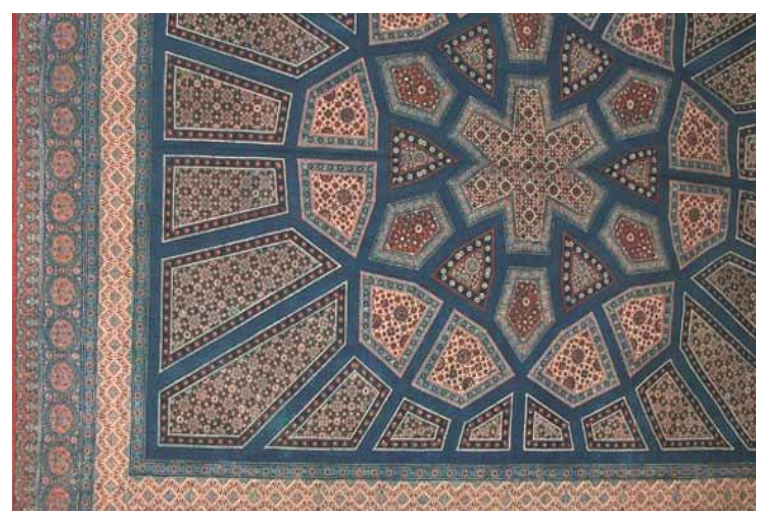

Figure 13:-Saudagiri Print

Number of Jaali patterns can be identified in Saudagiri blocks, which were inspired and taken by Mughal architecture. Just like in Mughal Jaalis the floral patterns in these block designs were made on the basis of geometrical grid.

BaghPrinting:Inthis type block of printing designs were really made and inspired by Jaalis of TajMahal and native Forts of Agra. Bagh Printing is a traditional printing technique where the natural colours and dyes are used. This craft is exclusively practiced in Bagh region of Madhya Pradesh (Figure 14). Migrants from Sindh in Pakistan brought this art to India.

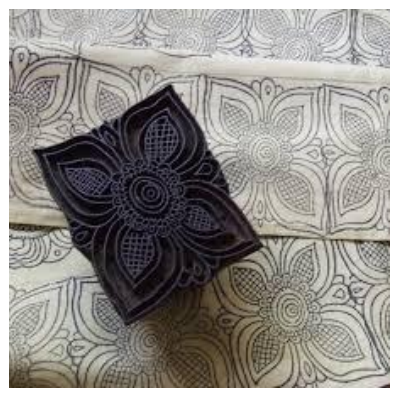

Figure 14:-Bagh Printing

Bagh designs are mostly made in geometrical and floral patterns and the carving of blocks is done by skilled block makers of Pethapur in Gujrat. In the present scenario Bagh Prints have made their way to global clientele in textile industry with wide-ranging variety of products.

Dabu Printing:A block printing which is carried out comprehensively throughout Rajasthan and done with mud resist technique. Variety of Jaali patterns is implied to create diverse deigns for the blocks.
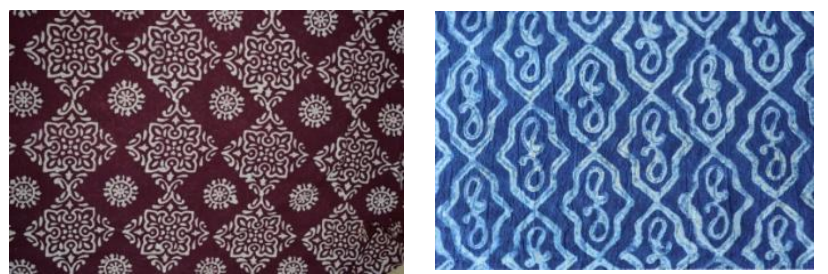

Figure 15:-Dabu Print

This technique employs a distinctive resist process prepared with mud (Figure 15). The designed portions are printed onto the fabric with dabu paste (mud paste), made by local clay, saw dust and guar gum. Later the fabric is dyed in desired colour. The printed fabric results in bright ground colour fabric. Numerous Jaali motivated motifs can be seen in this type of printing like, geometrical floral combinations and trellis. 
Block Printing of Bagru and Sanganer: Rajasthan is a state which carries an
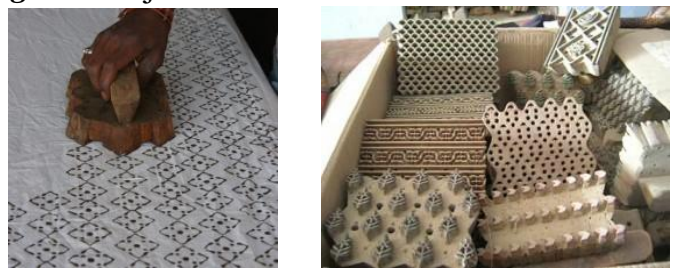

Figure 16:-Bagru and Sanganeri Printing

inheritance of fine block printed textiles. This particular craft is very common in Bagru and Sanganer near Jaipur in Rajasthan (Figure 16). The craft was originated by Mughal Printers during the rule of Jahangir and Shahjahan. This is the significant purpose of resemblance between the block and Jaali designs developed during this era. Jaali patterns and symmetrical trees in combination with calligraphy and inlay designs are the highpoints of this block printing technique.

\section{Weaving}

India devours the rich inheritance of woven textiles. Categorically the handlooms all over the nation constitute the major cottage industry of the country. Spread across the entire country each province has its own characteristic weave and style. A substantial effort is made to familiarize the Mughal Jaali patterns in the woven textiles of India.

Banaras Brocade: Banaras or Varanasi is a city renowned for its brocade and zari textile weaving with silks in the state of Uttar Pradesh Initially. The skill was developed by the migrants from Gujrat during $17^{\text {th }}$ century, who transformed this craft of weaving to new heights in Mughal period, mainly under Akbar's rule.
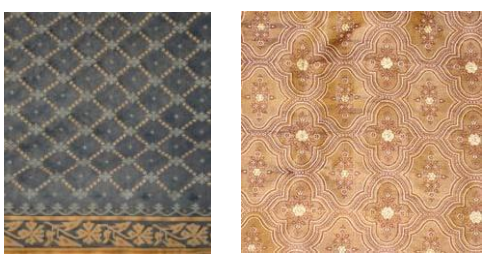

Figure 17:-Jamdani and TanchoiSarees with Jaali Pattern

Though the Banaras Brocade is well-known for its woven 'Butas and Butis', but with the Mughal influence in $16^{\text {th }}$ century, Islamic patterns like floral and Jaalis came into practice, predominantly with geometrical patterns. Gorgeous Jamdanis and sophisticated Tanchois are few of the brilliant examples of Banaras Brocade (Figure 17).

\section{Use of Mughal Jaali Patterns on Contemporary Textile Products:-}

Following is the brief look of the study done on some contemporary textile products prevalent in textile industry:

Sample 1: (Figure 18) An extravagant and graceful net saree which is a combination of Chanderi Fabric, Mughal Jali design in repeat and the weaving done by Banaras (now Benaras) weavers. This product is specially designed for the Indian festive season exclusively for an e-store known as Jaypore.

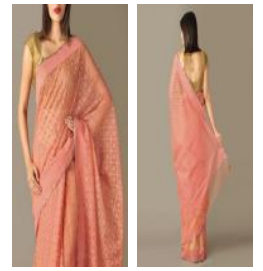

Figure 18:-Sample 1 Woven Jaali

Sample 2: (Figure 19) An elegant durrie of 3' x 2' dimension is again hand-woven on the loom, and designed for the same store Jaypore. Durrie is designed with monochrome Mughal Jali pattern which is robustly simple yet striking. 


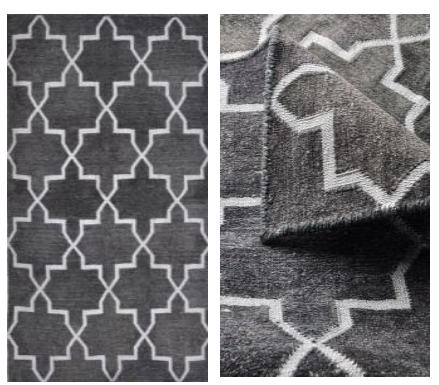

Figure 19:-Sample 2 Woven Jaali

Sample 3: (Figure 20) A mini Jaalikurta is designed by a well-known Apparel Store called Fab India. The beauty of the Jaali weave on this outfit is that it breaks the fabric into lacelike dots transforming it into a miniature lattice. Fabric is composed by a plain weave with the alternate Jali weave placed in decorative vertical stripes incorporating the yarns in tonal shades from the base color of the fabric.

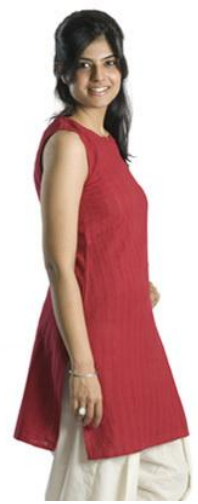

Figure 20:-Sample 3 Woven Jaali

Sample 4: (Figure 21) The magnificence of Mughal architecture remarks its presence on this cushion cover made of silk. The macramé technique is used to create the the geometrical patterns in hexagonal form on surface of the fabric to signify the Jaali screens of the Mughal. This classical piece of art is sold by the store named Window Passions.

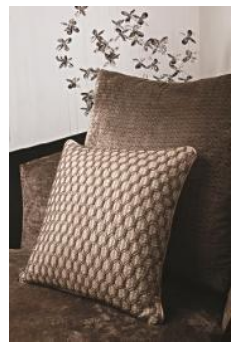

Figure 21:-Sample 4 Woven Jaali

Sample 5: (Figure 22) An Ikat design fabric constructed by the master weaver from Putapakka, Nalgonda district of Andhra Pradesh. He has woven this fabric completely inspired by the Mughal Jaali pattern found in monuments of Agra.

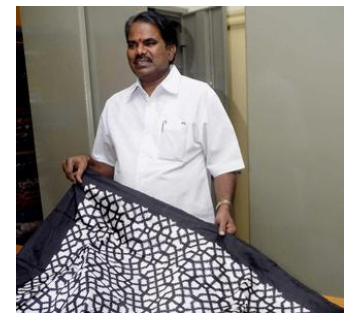

Figure 22:-Sample 5 Woven Jaali

Sample 6: (Figure 23) The Jacquard fabric is a woven yardage, manufactured by the company named 'Decorative Fabrics Direct'. The company has created a range of collection and wide variety of woven patterns based on Mughal Jaali theme in different shades and fabric. The fabrics are customarily available in yardages. 


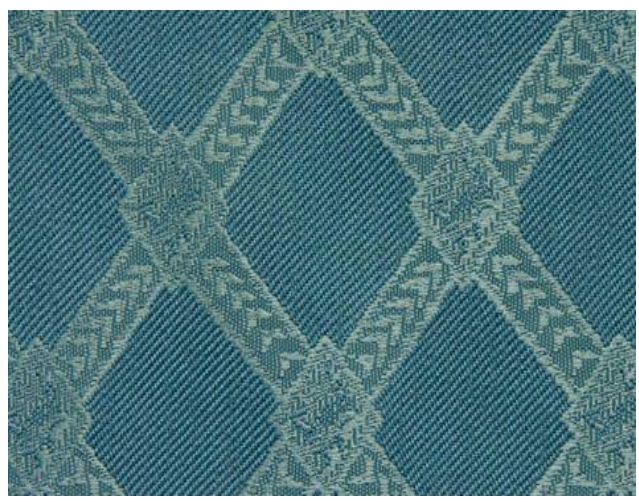

Figure 23:-Sample 6 Woven Jaali.

Sample 7: (Figure 24) An export house named Enkay Products at Agra has designed and manufactured variety of bags with a touch of Mughal Jaali patterns. The bags are tailored and patterned with woven jacquard fabric. Company has also produced some other products like apparels, accessories and footwear with an element of Mughal Jaali designs.
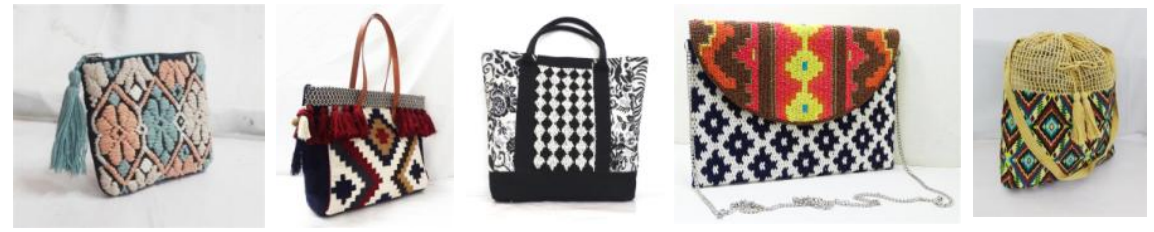

Figure 24:-Sample 7 Woven Jacquard Bags with Mughal Jaali Element

Sample 8: (Figure 25) This particular collection was launched by designer Rahul Mishra in International Wool mark Collection. The designer has used Merino wool and a blend of silk which has brought a new twist in the Chanderi weaving technique. The outstanding
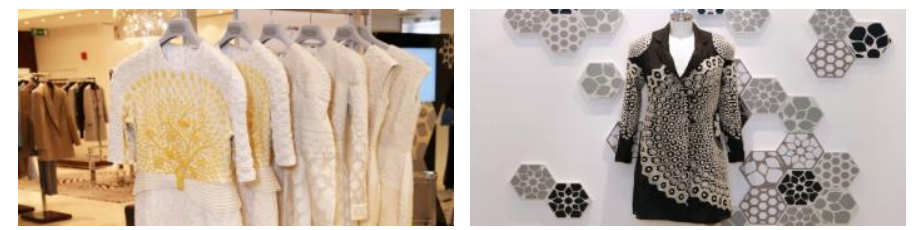

Figure 25:-Rahul Mishra's Woven Collection

hexagon pattern is structured by using the extra weft insertion technique; which is so much like doing hand embroidery with woolen yarn on the loom.

\section{Results:-}

The objective of this research papers was to categorize Mughal Jaali designs of Agra's Mughal Monuments and their application on textile products by various means of textile design techniques. The study was aimed to connect to the country's iconic heritage found in the form of Jaali patterns, which are extremely beautiful, decorative and constructed in the incredible Mughal architectural city of Agra.

\section{Following attention was given to conduct the research}

- To explore the different types of Jaali patterns of Mughal Monuments of Agra with respect to their foundation and style.

* To identify these patterns on different traditional textiles of India.

* To observe the stylization of these patterns on present day textiles.

* To make a comparison between the application of these patterns on traditional and contemporary textiles.

* To generate a linkage between the historical culture and their awareness in latest textile designers.

* To create a background for the textile design students to comprehend the historic foundations on which the creative practices are constructed.

Enduring historical motifs and designs offer an instrumental research source for the designers in the creative field. Conjoining contemporary styles with classical designs and motifs confirm the fortitude of these motifs in future. Products such fashioned in today's world have a vital role in maintaining cultural and historical standards. 


\section{Suggestions and Recommendations:-}

In this study various Mughal Jaalis of Agra and their execution on textiles was studied. All through the study it was understood that such patterns have always been an abundant resource for the design projections in creative fields and would even prove to be more resourceful if advanced with technical and artistic perceptions by new and traditional techniques.

Following prospects were considered to be advantageous for the future references in context with textile design and Mughal Jaalis:

Academic Prospects:-

* The classical designs of the ancient Monuments should be preserved to re-vitalize and re-interpret the age old outstanding designs.

* Young designers should be given a support to examine the influence of historical and social forces on modern designing.

* Create a background in the form of syllabi and curriculum for the design students to know the historic fundamentals which instigate the creative practices.

* Study of Mughal Jaalis may bring out effective results in design education and creative practices.

\section{These projections would impart better results if there will be:-}

* Extensive documentation of Jaali patterns with reference to various crafts (like, interior, furniture, textiles etc.) in a form of digital library of textile designs.

* Stylization of Designs depending on the requirement of various techniques (like embroidery, printing, weaving, painting etc.)

\section{Commercial Prospects:-}

* Potential stylization for execution of these designs on various products with diverse traditional crafts like embroidery, weaving, printing, painting, and dyeing.

* Enhancement of individual artistic and technical skills by introducing new possibilities in concepts in inspirational designing.

* Research in textile and fashion design with specific emphasis on Mughal Jaalis of Agra as one of the resource of learning design will cultivate strong interfaces in the two creative fields of design.

\section{Findings:-}

* The elucidation and endurance of Mughal Jaalis of Agra in textile design practices is constantly being used as influences, for adaptation, implementations and illustrations.

* It is perceived that the interdependence between historic pattern and contemporary practices of design is giving way to revitalization, at the same time renewal of the same patterns.

* Historic design influences can be included in theoretical data for designs, their current practices with wide variety of techniques and investigation through the traditional and modern designing.

* Practice and execution of Mughal Jaali designs of Agra is proving to be most innovative and utilizing in the area of textile design.

- Databases or data banks can be established with the collection of patterns and designs taken from various monuments and heritage sites that can be further aided to the users to utilize the designs in the finest conceivable way in their own creative fields.

\section{Conclusion:-}

Historical designs have constantly been a basis of inspiration for the modern designers. One such reason of historical inspiration is the Mughal Jaalis of Agra. Products fashioned with such inspiration have an imperative role in conserving cultural and historical values. Combining modern styles with age old designs and motifs confirm the subsistence of these motifs in future.

Regenerating historical designs and motifs offer a valuable research resource for the new budding designers in the field of textile industry. The study discovered the use of historic Jaali designs of Mughal Monuments of Agra and resulted in some noteworthy and unidentified facts of traditional and existing collections in textile design field. It is investigated that how the historical research motivate fresh designers and new generation to instill their ideas constructing inventive connections between historical and present period. 
After exploring the use and application of Jaalis of Mughal Monuments of Agra, it can be concluded that these designs are being used in many fields of Textiles in traditional as well as modern form and still are the most preferred design inspiration conceptions for the creative industry. It is evaluated that influence and adaptation of these designs is not only limited to our native market but has gone faraway up to Western and European countries surviving the heritage of our yester years alive. The multidisciplinary approach to create newer designs with regard to various techniques offers an innovative contribution to the field of creative practices. Mughal Jaalis had been and still remain one of the most resourceful inspirations in the field of Textile Design. After studying the development of Mughal Monumental Jaalis of Agra all through the history, it is concluded that the execution of these motifs in various textile crafts brings together the examples of inspired modern creation, reinterpretations and retranslations. Motivated from Mughal monuments, the designers today continue to explore, rejoice, and reproduce our rich indigenous substantial legacy.

\section{References:-}

1. (n.d.). Retrieved from www.indiatoursonline.

2. Artistic Elegance in Mughal Buildings. (n.d.). Retrieved July 5, 2015, from prr.hec.gov.pk

3. Asian and African Studies Blog. (2013, April 29). A Farewell to the Mughals. Retrieved August 5, 2015, from britishlibrary.typepad.co.uk

4. Awartini, D. (n.d.). The Crucial Role of Geometry in Islamic Art. (M. Bovaissa, Interviewer)

5. Deepika, G. (n.d.). DNA. Retrieved 2015

6. Geometric Design in Islamic Art. (n.d.). Retrieved August 6, 2015, from www.metmuseum.org.

7. Graffiti. (2013). Mughal Magic. Retrieved 2015

8. H, F. C. (n.d.). Traditional Material use in a Digital World: A Creative Design Methodology. Retrieved August 24, 2015, from www.sd.polyu.edu.hk.

9. Helen, L. T. (2011, April). The ossible Combination of Traditional and Contemporary Textile Printings.

10. Islam and Architecture. (n.d.).

11. Islamic Art and Geometric Design Activities for Learning. (n.d.). Retrieved August 8, 2015, from britton.disted.camosun.bc.ca

12. Islamic Art, CAABU. (n.d.). Retrieved August 7, 2015, from www.caabu.org.

13. Jadunath, S. (n.d.). Glimpses of Mughal Architecture.

14. Jali. (n.d.). Retrieved 2015, from www.rural housingnetwork.in.

15. Jasleen, D. (n.d.). Asian Embroidery. Retrieved August 12, 2015, from https://books.google.co.in

16. Kartin, E. (2011, June 13). The Story of Scandivian Design: Combinig Function and Aesthetics. Retrieved August 7 , 2015, from www.smashingmagazine.com.

17. Kunal, M. (n.d.). New Fashion Flavours.

18. Martin, L. (n.d.). The Flame and The Lotus: Indian and Southeast Asian Art from Kronos. Retrieved July 25, 2015, from https://book.google.co.in

19. Monika, Z. (2014, September 30). Facts and Myths About Digital Creating. Retrieved August 24, 2015, from designtutsplus.com.

20. Zarch, H. (n.d.). Islamic Art. Retrieved August 2, 2015, from www.bbc.co.uk

Websites Referred:-

1. http://www.tradeindia.com

2. http://www.betterinteriors.in

3. http://www.decorativefabricsdirect.com

4. http://www.harveynichols.com

5. https://www.behance.net

6. http://chattra.com

7. https://www.jaypore.com/

8. http://www.thehindu.com

9. www.infoplease.com

10. www.encyclopedia.com

11. www.dnaindia.com

12. www.gjournals.org

13. www.mapsofagra.com

14. www.worldvisitguide.com

15. www.coroflot.com 